\title{
$\mathbb{A}$ Economics Bulletin
}

Volume 28, Issue 21

Research Announcement

\section{Causes of Inflation in Turkey: A Literature Survey with Special Reference to Theories of Inflation}

\author{
Aykut Kibritcioglu \\ Ankara University and University of Illinois at Urbana-Champaign
}

\begin{abstract}
Turkey has experienced high and persistent inflation for more than twenty years. This paper attempts firstly to survey the extremely broad literature on theories of inflation. It is mainly argued that inflation may be interpreted as a net result of sophisticated and continuous interactions of demand-side (or monetary) shocks, supply-side (or real) shocks, price-adjustment (or inertial) factors and political processes (or institutional factors). The second aim of the paper is to compare the existing empirical studies on Turkish inflation, by considering their sample period, data frequency, empirical methods, modeled macroeconomic variables and main results.

Published as a working paper in University of Illinois at Urbana-Champaign, College of Commerce and Business Administration, Office of Research Working Papers, No. 01-0115.

Paper is available at URL:

Aykut Kibritcioglu

Ankara University and University of Illinois at Urbana-Champaign

kibritci@politics.ankara.edu.tr

484 Wohlers Hall, 1206 South Sixth Street

Champaign, 61820, USA
\end{abstract}

Citation: Aykut Kibritcioglu, (2001) "Causes of Inflation in Turkey: A Literature Survey with Special Reference to Theories of Inflation", Economics Bulletin, Vol. 28 no. 21 p.A1.

Submitted: October 30, 2001 Published: October 31, 2001.

URL: http://www.accessecon.com/pubs/EB/2001/Volume28/EB-01AA0025A.pdf 